evidence is insufficient to show whether corticosteroids or methotrexate are to be preferred, but slightly favours the latter. There is much to be said for not prolonging treatment with these agents or for using heroic doses to try to achieve a complete remission. It is better to restrict treatment to the control of the immediate life-threatening situation.

The original case reported in 1910 by von Zumbusch, ${ }^{5}$ whose name is usually linked with this disease, survived nine attacks of generalized pustular psoriasis of decreasing severity. Whether this would have been the outcome had modern methods of treatment been available is problematical.

\section{Faecal Incontinence}

One of the most distressing of disabilities is anal incontinence. Among its many causes may be specially noted the scarring of an extensive perineal tear in childbirth, ill-contrived anal surgery, spinal cord trauma or disease, and severe rectal prolapse, and may or may not be complicated by urinary incontinence. The patient, often an elderly woman, becomes cut off from family and friends, a nuisance in an old people's home or hospital for patients with chronic diseases, and more liable than others to develop pressure sores.

Until recently little could be offered to many of these patients, but K. P. S. Caldwell and his colleagues at Exeter ${ }^{12}$ made an important advance when they developed the idea of continuous stimulation of the anal and vesical sphincter muscles by means of indwelling electrodes. The first patient subjected to this technique was a 60 -year-old woman who had been incontinent of faeces for 23 years after a tear during childbirth. Electrodes were implanted surgically in the anal sphincter together with a subcutaneous secondary coil. A radio-frequency linkage was used to convey tetanizing current from an external stimulator. After two months full control was restored. In the second case, a man with an injury to the cauda equina was rendered continent of urine by implanting electrodes via a suprapubic approach into the external urethral sphincter. B. R. Hopkinson and R. Lightwood, ${ }^{34}$ at Birmingham, devised an external stimulating apparatus to obviate the need for surgical implantation of the electrodes. The device is placed in the anal canal and held there by means of the contraction induced by the stimulating current. A dumb-bellshaped Perspex appliance carries two parallel ring electrodes placed $1 \mathrm{~cm}$. apart. It is connected to a portable tetanizingcurrent generator the size of a large matchbox, which is fastened to the patient's underclothes by means of a safetypin. Transistor-radio batteries provide a power supply which lasts for a week. Preliminary results are encouraging. Encouraging results from this technique have now come from the U.S.A. also. B. H. Fischer and H. A. von der $\mathrm{Mosel}^{5}$ report from New York on the use of a very similar external stimulating apparatus in six patients rendered incontinent of faeces as a result of neurosurgical procedures. Prompt and full control of bowel movements was obtained in five of the

1 Caldwell, K. P. S., Lancet, 1963, 2, 174.

2 Caldwell, K. P. S., Flack, F. C., and Broad, A. F., Lancet, 1965, 1, 846.

3 Hopkinson, B. R., and Lightwood, R., Lancet, 1966, 1, 297.

4 Hopkinson, B. R., and Lightwood, R., British fournal of Surgery, $1967,54,802$.

5 Fischer, B. H., and von der Mosel, H. A., fournal of the American Medical Association, 1969, 207, 1897. patients, but there was failure in the sixth because of unsuitable shape and size of the electrode.

This simple technique is likely to have increasing application in the control of anal incontinence. For some patients it will restore sphincter control; for others it will make life more tolerable.

\section{Representation of Junior Doctors}

In losing a battle the hospital junior doctors have gained sympathy for their cause. As reported in the Supplement, the Representative Body at Aberdeen was asked to create a standing committee of the Association for hospital junior staff to, among other things, dispel the belief that their interests are neglected by the Central Committee for Hospital Medical Services. Several speakers emphasized how widespread is this view among junior medical staff, and pressed that the Association should destroy the myth by showing its willingness to meet their requests. For most the plea was not that justice was not being done ; it was that it should obviously be seen to be done. Agreement to a standing committee for hospital junior staff was described by Dr. J. F. G. Pigott, chairman of the Junior Hospital Doctors' Association, as the one remaining ground of conflict between the J.H.D.A. and the B.M.A.

Many of the 14,000 junior doctors can rightly point to their relative seniority and to their heavy work-load. Doctors are often not appointed to a consultant post before their mid-thirties, and many "junior staff" are nearer 40 than 30 . Where else except in medicine are graduates of this maturity still called "junior," and treated as such ? It is certainly not the case in industry, nor was it in the two world wars. The future of postgraduate medical education, the career structure open to them, and the form the N.H.S. itself will take all vitally affect junior doctors, and rightly they wish to contribute to this reshaping. They have already contributed usefully to the Association's affairs, and if all junior doctors threw their weight behind the B.M.A. they could undoubtedly contribute even more effectively than in the past. This they would surely concede.

By its vote of 180 to 164 against a standing committee the Representative Body was far from giving the spokesman for the junior doctors a direct rebuff. The closeness of the vote showed the Meeting's real understanding of their sense of inferior status. But the vote also recognized that a sentiment of this kind, however powerful, was a poor reason for making a change. The junior doctors are already well represented in the Association and their voice has been clearly heard. Moreover, Mr. Walpole Lewin, the Chairman of the C.C.H.M.S., has stated his committee's readiness to see what more could be done to improve matters. A new committee created in parallel with the C.C.H.M.S. could easily have jeopardized effective negotiation with the Government. Such political ping-pong on a triangular table, as one speaker put it, would lead to further division, delay, and opportunity for those in authority to divide and rule. Young doctors will stay in Britain only if they can see long-term prospects of a satisfying career. The B.M.A. has a good chance to guarantee this future if it can negotiate for the whole profession. The profession can ill afford to dissipate its energies in sectional disputes when it has so much else on hand that requires its united energies. 